\section{Prof. M. N. Saha, F.R.S.}

Prof. Meghnad Saha, who, as is recorded elsewhere in this issue, has been elected president for the current year of the National Institute of Sciences of India, is among the foremost of Indian physicists. $\mathrm{He}$ is chiefly known for his theory of stellar spectra, which he put forward in 1920 during a period of research with Prof. A. Fowler at the Imperial College of Science, London. In that theory, which began with a consideration of the solar spectrum and was afterwards extended to the spectra of the stars in general, Saha brought together the thermodynamical theory of ionization of atoms, at that time little known in England, and the observational indications of various degrees of ionization in stellar atmospheres found by Prof. Fowler and others. This formed the starting-point of a vigorous attack on the problems of stellar atmospheres, in which Profs. R. H. Fowler and E. A. Milne in England, and H. N. Russell in America, have taken a prominent part. The result of this work has been not only a partial solution and the establishment of a definite viewpoint for the further examination of stellar atmospheric problems, but also the creation of a closer relationship between laboratory and astronomical physics, for in the light of Saha's theory certain atomic properties, for example, the duration of the excited state of an atom, can be determined from astronomical observation as well as, if not better than, from terrestrial experiments. Prof. Saha has also made other useful contributions to theoretical physics, and is the author of an imposing text-book on the subject.

\section{British Chemical Industry and European Affairs}

EUROPEAN affairs in relation to the chemical industry, and particularly to the British chemical industry, recently formed the subject of an address by Dr. H. Levinstein to the Institution of Chemical Engineers. If and when war comes it would, he said, be sudden and overwhelming, whilst industries unprepared for war could not be switched on to the requirements of war without great delay and immense cost. In 1914, war was not expected by the British chemical industry. Dr. Levinstein outlined some of the urgent requirements which the industry then had to face, and referred to some of the great deficiences, delays, and difficulties with which it had to contend. That it eventually surmounted these difficulties and removed these deficiencies is attested by military history, but, said Dr. Levinstein, "I have said enough to show the terrible delay, prolonging suffering and death, inevitable to going to war with our chemical industries as they were in 1914". On the other hand, "the German Government had the nucleus of a strongly centralised and organised industry for the chemical side of the production of munitions of war". The formation of Imperial Chemical Industries, Ltd., and the establishment of the Institution of Chemical Engineers are two de-velopments of importance in the present organization of British chemical industry. "We may be thankful," he said, "for it is of great national importance, that the chemical industry is to-day more closely knit. . . .
We are not so unprepared in all matters as may sometimes be thought. At least in the chemical industry we are stronger in every branch; more compact in structure, more complete in scope, with large units ably directed." The chemist has his responsibility, as a citizen, to help in removing the causes of war; but likewise his responsibility for ensuring an adequate defence against aggression is great. Dr. Levinstein has assured us that in Great Britain the chemical industry is not asleep.

\section{Royal Commission for the Exhibition of I85I}

IN consequence of the Government's decision in 1935 to forgo any further contributions from the capital resources of the Royal Commission for the Exhibition of 1851 towards the cost of new buildings for the Science Museum, and owing to other factors that have lately tended to stabilize the Commissioners' income for some years to come, the Board of Management of the Commission has been able to set aside sufficient to provide for an additional annual scholarship of two or three years' duration. This will be used to extend to India the scheme of science research scholarships for overseas universities, each of which is of the annual value of $£ 250-£ 280$. To those who have watched the growth of post-graduate studies in India this decision has naturally given great satisfaction, and the allotment of even a single scholarship has been warmly appreciated by the Indian universities. Indian students have, of course, always been eligible for the coveted senior studentships, of which five are awarded each year by the Commissioners to advanced students of science nominated by universitios in Great Britain. But until now they have had no chance to participate in the benefits of the overseas scholarships, which have been the means of training in the methods and technique of research and thus equipping for responsible positions in the scientific service of the Empire so much first-rate talent from the universities of Canada, Australia, New Zealand, South Africa and the Irish Free State. Moreover, these awards, of which eight have been made each year, provide a valuable link between research scholars of this country and the Dominions. From this point of view also the inclusion of India in the scheme is of considerable importance.

The Commissioners' research scholarships scheme, since it was first established in 1891, has, through its beneficiaries, achieved a noteworthy reputation. Of some six hundred past scholars, the majority now occupy positions of the highest rank in almost every branch of scientific activity. University life in Great Britain and the Dominions has been greatly enriched by the men and women trained under the auspices of the Commission. If rather more than half the scholars have distinguished themselves as principals, professors or lecturers in the academic world, the heads of many industrial laboratories and of Governnient technical establishments at home and abroad have also been recruited from the same source. No less than forty-one scholars have been elected to 
fellowship of the Royal Society and four of them have received Nobel prizes. This side of the Commissioners' work-and it is by no means the only side-is perhaps the most notable of their achievements since under the inspiring lead of the Prince Consort they set themselves their first task of developing as a great educational centre the property purchased at South Kensington with the proceeds of the Great Exhibition.

\section{The Institute of Metals}

Two important announcements were made by the president of the Institute of Metals, Mr. W. R. Barclay, at the annual general meeting on Wednesday, March 10. The first dealt with co-operation with two sister institutes. As a first step in a scheme of co-operation with the Iron and Steel Institute, members of each Institute can become members of the other without formality other than written application. Combined annual subscriptions and entrance fees have also been arranged. The present scheme of co-operation follows one recently completed by the two Institutes with the American Institute of Mining and Metallurgical Engineers whereby members, associates and student members of the British Institutes may, if under the age of thirty-three years, become junior foreign affiliates of the American Institute of Mining and Metallurgical Engineers on specially favourable terms, the arrange$m \in n t$ being reciprocal in the case of members of the American Society. The president also announced that the Council had decided to issue an appeal for the creation of an Endowment Fund, to be invested for the support and extension of the work of the Institute. For the last few years the margin between income and expenditure in the annual accounts had been very narrow, and had afforded little or no opportunity to strengthen the Institute's financial reserves. Economies had been effected wherever possible, but these could not be extended without seriously curtailing the service the Institute renders to its members and to the industry in general. In the judgment of the Council the time had arrived when, on the basis of the record and achievements of the Institute, an appeal could and should be made to the non-ferrous metals industry for a substantial capital sum which it was hoped would appreciably lessen the anxiety constantly felt by the Council and its committees as to the financial future. He was glad to be able to announce that promises or actual contributions amounting to about $£ 14,000$ had already been received.

\section{Prehistoric Cultures and Chronology in North Africa}

THE most recent contribution of M. R. Vaufrey to discussion of a group of chronological and cultural problems in the archæology of North Africa, of which an account appears in another column of this issue of NATURE (see p. 432), is of more than local interest in its bearing on questions of wide import in the study of prehistoric civilizations. M. Vaufrey, the distinguished anthropologist who occupies a chair in the Institut de Paléontologie humaine in Paris, has explored extensively over a number of years among the prehistoric sites of North Africa, and his studies in the classification of the cultures and in the prehistory of that region are accorded the authority due no less to his meticulous precision as an investigator in the field than to his ability in the analysis of archæological evidence recorded by others. In his latest contributions to a subject upon which no one is thus better qualified than himself to speak, M. Vaufrey has two main objectives.

IN the first place, M. Vaufrey's aim is to determine with such precision as the case warrants the cultural association and dating thereby of the 'fossil' man of Mechta el-Arbi, a problem of no little moment in the history of the development of early types of 'modern' man in the Mediterranean area; and secondly, to determine the age which should be assigned to the characteristic art form of prehistoric North Africa, the rock engravings of varied forms of animal life in naturalistic style, a question long a matter of controversy among archæologists, of which the suggested solutions have ranged from the palæolithic to the Iron age or later. By his conclusions that this type of early man belongs to the Mesolithic age and even later, the early Neolithic, while the cultures with which he is associated, by correlation with the early civilizations of the Nile valley, can be fixed in terms of years at a period extending from the beginning of the fourth millennium, down to the middle or even the end of the second millennium B.C., M. Vaufrey arrives at a result which will be of the first importance when brought into relation with the study of mesolithic and early neolithic cultures throughout the whole range of cultural distributions in the ancient world.

\section{Prehistoric Caves in Kent}

A RECEnT subsidence of earth at St. Mary Cray, Kent, has revealed the existence of a subterranean cavity, which, it is thought, may prove to be the entrance to a considerable system of caves, similar to that at Chislehurst, two and a half miles away to the south, where thirty miles of galleries have been explored since the caves were rediscovered in 1902 . Marks of deer-horn picks, still clearly visible, show where prehistoric man cut away the chalk. Although it will not be possible to attempt to explore the caves at St. Mary Cray until the fallen subsoil has been removed, entrance to two chambers, it is stated in The Times of March 4, has been made by Mr. GibsonCowan and Mr. Geoffrey Edwards, who found them to be about five feet high by thirty feet long. Probing with a pole ten feet long at the end of the farther chamber failed to encounter obstructing chalk, and it may be concluded, therefore, that they extend in this direction, while the existence of an earlier subsidence a quarter of a mile away, suggests that there may be a system of connected caves of considerable extent. The Chislehurst caves have produced few archæological relics; but as an Elizabethan villa has been shown to have had direct access to the caves by means of a stair, and the caves were used as refuges, 